\title{
Interactive comment on "Image Processing Based Atmospheric River Tracking Method Version 1 (IPART-1)" by Guangzhi Xu et al.
}

\section{Anonymous Referee \#1}

Received and published: 29 June 2020

The manuscript introduces a novel algorithm to detect and track atmospheric rivers. Unlike most of the existing AR detection algorithms, this algorithm is magnitudeindependent which makes it less sensitive to changes in IVT/IWV in the future climate. This algorithm is capable to detect weaker systems and identify more completed AR life cycles.

The manuscript is well-constructed with detailed explanations of each step and sensitivity tests on parameter choices and other detection algorithms. I don't have any major concerns about this manuscript. Please see the following as my minor comments:

Printer-friendly version

Discussion paper

Comments: 1. It would be helpful to mention in the introduction that different magnitude thresholds also cause uncertainties in AR measures with reanalysis (as mentioned in ARTMIP publication), not only in future ARs 2. L 44-45: I don't think this is a disadvan- 
tage because some detection methods focus on understanding the landfalling impact of ARs - an absolute threshold will be quite informative and has implications for water management. Depending on scientific questions, the most suitable method changes. 3. Figure 3: it would be great to mark latitudes and longitudes. 4. L245: Are the tropical reservoirs removed by the algorithm through geometric filtering or they are counted as AR candidates? 5. Figure 9: what does inf duration mean?

Minor: 1. L51: "filamentary"?

Interactive comment on Geosci. Model Dev. Discuss., https://doi.org/10.5194/gmd-2020-135, 2020. 